\title{
So You Want to Be a Neuroscientist?
}

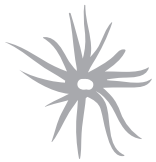




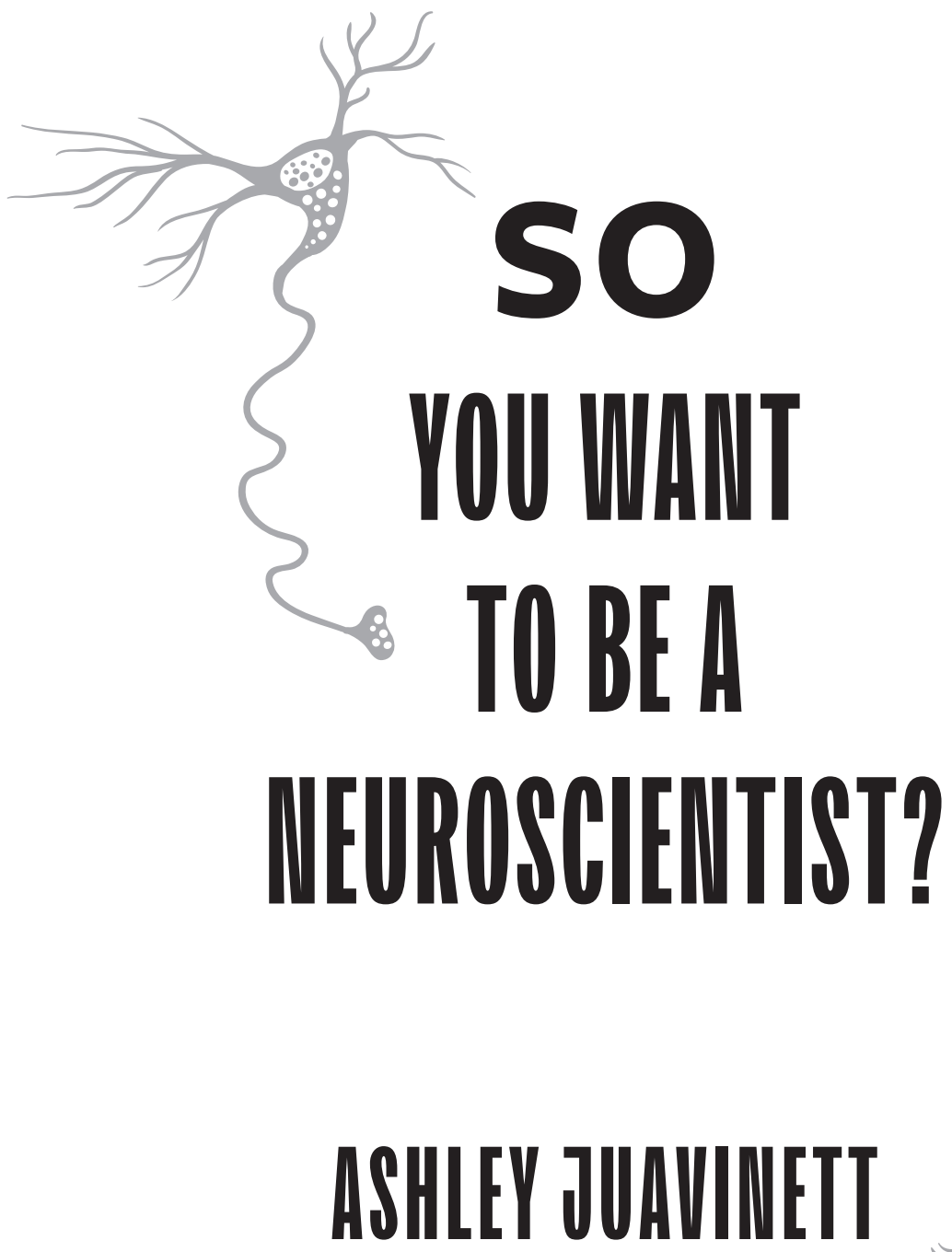

COLUMBIA UNIVERSITY PRESS

New York 


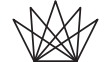 \\ Columbia University Press \\ Publishers Since 1893 \\ New York Chichester, West Sussex \\ cup.columbia.edu}

Copyright () 2020 Columbia University Press

All rights reserved

Library of Congress Cataloging-in-Publication Data

Names: Juavinett, Ashley, author.

Title: So you want to be a neuroscientist? / Ashley Juavinett.

Description: New York : Columbia University Press, 2021. |

Includes bibliographical references and index.

Identifiers: LCCN 2020018743 (print) | LCCN 2020018744 (ebook) |

ISBN 9780231190886 (hardback) | ISBN 9780231190893

(trade paperback) | ISBN 9780231549158 (ebook)

Subjects: LCSH: Neurosciences-Vocational guidance.

Classification: LCC RC 343 .J73 2021 (print) | LCC RC 343 (ebook) | DDC

$616.80023-\mathrm{dc} 23$

LC record available at https://lccn.loc.gov/2020018743

LC ebook record available at https://lccn.loc.gov/2020018744

Columbia University Press books are printed on permanent and durable acid-free paper.

Printed in the United States of America

Cover design: Lisa Hamm 
To the future brain explorers... this is your land, too.

常 
